\title{
Caracterização de polímeros
}

\section{INTRODUÇÃo}

$\mathrm{Se}$ "a caracterização descreve os aspectos de composição e estrutura (incluindo defeitos) dum material, que são significativos para uma preparação particular, estudo de propriedades ou uso, e são suficientes para a reprodução do material" (definição emitida pelo "Committee on the Caracterization of Materials da U.S. National Academy of Sciences") pôe-se a questão de saber se existe alguma maneira de caracterizar de forma inequívoca (ou suficiente para a reprodução do material), materiais tão complexos como são os polimeros. Dir-se-à que uma caracterização absoluta implica o conhecimento da natureza de todas as moléculas presentes e da maneira como se dispøem. Na realidade, o que se faz normalmente é encontrar um material polimérico que satisfaça um determinado objectivo e determinar nele certos parâmetros estruturais e quantificar algumas propriedades relacionadas com aqueles, de modo que o fornecedor e aplicador possam sistematicamente verificar essas características.

As características intrínsecas dum polímero derivam de:

- natureza química das suas moléculas

- natureza macromolecular (cadeias longas) e elevados pesos moleculares

- distribuição dos pesos moleculares

- disposição das cadeias, umas em relação às outras (morfologia)

O conhecimento daquelas características, possível para casos simples, macromoléculas lineares, complica-se com situaçð̄es de ramificaçðes curtas e longas da cadeia, tacticidade, modo de adição de monómeros, polaridade dos monómeros e comonómeros etc.

Perante estas dificuldades a caracterização faz-se através de ensaios mais ou menos normalizados e comparação com padrôes, fugindo de certo modo, às complicaçð̃es da caracterização estrutural.

Postas estas consideraçð̄es gerais vejamos alguns métodos fundamentais e outros de carácter prático, expeditos, de fácil aplicação em controlo industrial para a caracterização de polímeros, no campo molecular e morfologico.

\section{1- CARACTERÍSTICAS ESTRUTURAIS}

\section{1 - Definições}

Peso molecular e distribuição de pesos moleculares. Para uma cadeia composta por $\mathbf{n}$ unidades monoméricas A de massa molecular $\mathrm{m}_{\mathrm{A}}$ vem:

Massa molecular $M=m_{A} \times n(n=D P$ grau de polimerização)
Num polímero sintético (salvo raras excepçð̃es correspondentes a condiçðes de polimerização especiais), existe uma mistura de "espécies" de massas moleculares diferentes, isto porque o comprimento das cadeias (grau de polimerização) não é constante.

Considerando peso molecular como um número abstracto que exprime a massa de uma molécula tomando como referência o Carbono 12, podem para os polímeros, definir-se diferentes tipos de pesos moleculares.

Assim:

$M_{n}=\frac{\sum_{i} M_{i} N_{i}}{\sum_{i} N_{t}}$ corresponde a uma média ponderada numericamente, enquanto que $M_{w}=\frac{\Sigma_{i} W_{i} M_{i}}{\Sigma_{i} W_{i}}=\frac{\Sigma_{i} N_{i} M_{i}^{2}}{\Sigma_{i} N_{i} M_{i}}{ }^{2}$ uma média ponderada massicamente.

$\mathrm{O}$ valor $\overline{\mathbf{M}}_{\mathrm{w}} / \overline{\mathrm{M}}_{\mathrm{n}}$ chama-se índice de heterogeneidade $\mathrm{e}$ dá uma medidă da dispersão dos pesos moleculares. Quanto mais próximo for de 1 o seu valor, mais homogéneo será o polímero.

\section{2 - Métodos de determinação de pesos moleculares} médios

\subsection{1 - Métodos baseados na medida da pressão osmótica}

Consiste em determinar a diferença de pressão entre uma solução diluída de polimero e o solvente puro, separadas por uma membrana que só deverá ser permeável às moléculas do solvente. As complicaçðes deste método provêm do facto das membranas serem também permeáveis às pequenas moléculas do polímero. A diferença de pressão depende somente do número de moléculas presente pelo que, este método permite obter $\bar{M}_{\mathrm{n}}$.

Métodos baseados na medida de outras propriedades coligativas dum modo geral conduzem à determinação de $\mathbf{M}_{n}$ e aplicam-se nos casos em que o peso molecular é relativamente elevado. Baseiam-se no abaixamento do ponto de congelação ou de pressão de vapor e na elevação do ponto de ebulição.

\subsection{3 - Análise dos grupos terminais das cadeias}

Os grupos terminais das cadeias podem por vezes ser analisados por métodos químicos ou físicos. Um caso clássico é a análise química dos grupos amina e carboxilo nas poliamidas. Este método conduz igualmente à determinação de $\overline{\mathbf{M}}_{\mathrm{n}}$.

\footnotetext{
aboratório de Aplicaçðes de Plásticos, Companhia Nacional de Petroquímica.
} 


\subsection{4 - Difusão de luz (Light Scattering)}

Esta técnica consiste em medir as diferenças de difusão de luz entre soluçôes de polimeros de diversas concentraçð̄es e sob diferentes ângulos de difusão.

A intensidade da luz difundida é proporcional ao quadrado da massa da partícula, donde o peso molecular médio obtido é $\mathrm{M}_{\mathrm{w}}$ (média ponderada massicamente ou peso molecular médio em peso). Uma das grandes dificuldades desta técnica (para além do custo do equipamento) é a remoção das partículas estranhas que igualmente difundem a luz.

\subsection{5 - Viscosidade em solução}

A partir de medidas de viscosidade em solução, de soluçð̃es de polímero sucessivamente diluídas, é possível determinar a viscosidade intrínseca $\left[\eta_{i}\right]$ que corresponde ao limite da viscosidade inerente $\left[\eta_{\text {in }}\right]$ quando a concentração tende para zero.

A viscosidade intrínseca está relacionada com o peso molecular pela fórmula [ $\eta \mathrm{i}]=\mathrm{K} \overline{\mathrm{M}}_{\mathrm{v}}^{a}$ (equação de Mark-Howink) em que $\bar{M}_{y}$ é o peso molecular médio viscosimétrico, muito proximo de $\overline{\mathbf{M}}_{w}$. $\mathrm{K}$ e $\alpha$ são constantes para cada par solvente/polímero.

\subsection{6 - Cromatografia por permeação ou por exclusão de volume}

É a técnica mais correntemente utilizada quer na determinação das diferentes médias de pesos moleculares como na sua curva de distribuição. Fundamentalmente é um processo de cromotografia líquida de alta pressão e, para alguns polímeros também de alta temperatura, que consiste em fazer passar uma solução de polímero por colunas cheias de material poroso, com poros de diversos tamanhos. As moléculas de polímero são absorvidas selectivamente, de acordo com o seu tamanho, a partir das mais pequenas para as maiores, sendo depois eluídas por ordem inversa e caracterizadas, à saí$\mathrm{da}$, por um qualquer método conveniente (índice de refracção, transmissão no infra-vermelho num comprimento de onda fixo, etc.). Obtém-se assim uma curva de distribuição de pesos moleculares, que é sem dúvida a característica "mais" fundamental dum polímero. Do que foi dito fica bem expresso que em GPC as moléculas são separadas pelos seus tamanhos pelo que este tipo de análise é também chamado SEC (Size Exclusion Chromatography). Deste facto resulta uma das principais dificuldades da aplicação deste técnica aos diversos polímeros pois que a quantificação do cromatograma exige uma calibração prévia que normalmente é feita com padrôes lineares de poliestireno. A transposição desta calibração para polimeros de natureza diferente e ramificados acarreta complicaçðes e erro pelo que tem havido tentativas de calibração com polimeros (padrסes) da mesma natureza e suficientemente caracterizados por outros processos. Mas em muitos casos, a obtenção destes padrōes e respectiva caracterização é extremamente difícil.

Contudo, apesar da relatividade dos resultados obtidos, a técnica de GPC é de longe a mais prática, a mais utilizada e que proporciona informação mais relevante no que respeita a caracterização molecular dos polímeros.

\subsection{7 - Medida de índice de fluidez}

A medida de indice de fluidez faz-se segundo um procedimento padrão; existem diversas normas para esta determinação e para a maior parte dos termoplásticos. É um método muito expedito de caracterização dos materiais, muito usado em controle de produção e dando boas indicaçбes para os transformadores.

Consiste em determinar a viscosidade do fundido em condiçð̋es pré-estabelecidas. Apresenta-se normalmente, no que respeita a unidades de medida, em g/10 minuto.

$\mathrm{O}$ índice de fluidez, como é evidente, não dá qualquer indicação sobre o valor médio do peso molecular embora o seu valor seja em grande parte, determinado por $\overline{\mathrm{M}}_{\mathrm{w}}$ com o qual varia em relação inversa.

\section{2-MORFOLOGIA}

2.1 - Morfologia é a ciência da forma e da estrutura. As longas cadeias dos polímeros podem dispor-se mais ou menos ordenadamente, conforme a sua natureza, donde resulta uma estrutura com diferentes graus de cristalinidade, entendendo por cristalinidade a disposição regular dos átomos e das moléculas.

Os polímeros podem ser parcialmente cristalinos como o polietileno e o politereftalato de etileno ou não cristalinos como alguns tipos comercializados de polimetilmetacrilato e poliestireno.

No caso dos polimeros cristalinos (assim chamados os parcialmente cristalinos) a obtenção de uma elevada taxa de cristalinidade obriga a que as cadeias sejam lineares ou com ramificaçôes de pequeno volume de modo que se integrem na estrutura ordenada sem a perturbarem, e que estas ramificaçōes se disponham duma forma regular ao longo da cadeia. Assim, na maior parte dos casos, os polimeros isotáticos e sindiotáticos cristalizam, o que não acontece (pelo menos na mesma escala) com os atáticos, com os ramificados e com os copolimeros. Verifica-se também que quanto maior é o grupo lateral menos cristalino é o polímero, muito embora haja regularidade de estrutura de cadeia molecular.

A partir de soluçðes diluidas de polímero, é possível obter monocristais. Estes têm sido obtidos para diversos tipos de polímeros e foi comprovado que estes cristais são formados por lamelas com uma espessura da ordem dos $100 \mathrm{~A}^{\mathrm{e}} \mathrm{e}$ com dimensðes laterais entre 1-10 $\mu \mathrm{m}$. No entanto a maior parte das vezes o que se reconhece é a existência de cristalitos numa matriz amorfa. Nos cristalitos as moleculas encontram-se dobradas, (modelo de KELLER) enquanto, que na parte amorfa se apresentam enoveladas e emaranhadas.

A Fig. 1 corresponde a uma representação esquemática da estrutura mencionada.

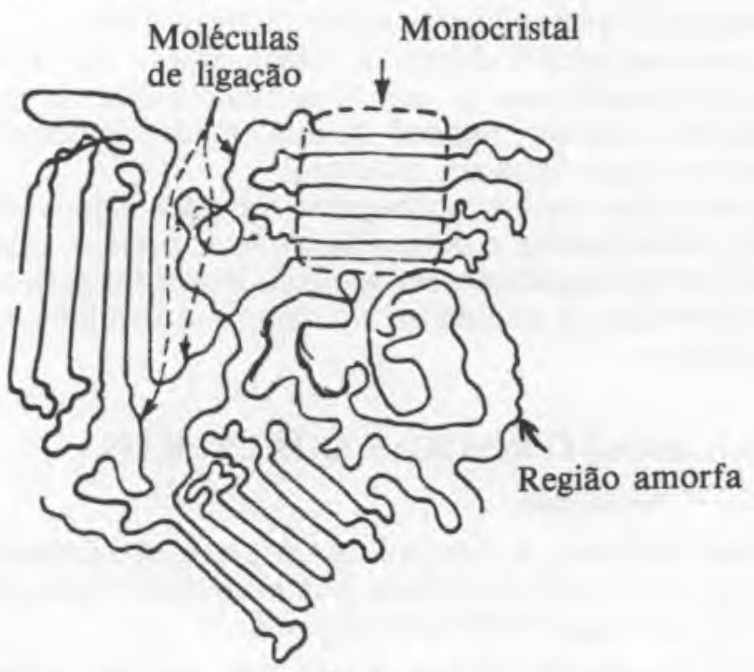

Fig. 1

Representação esquemática do modelo monocristal - regiāo amorfa 
Quando um polímero cristalizável é arrefecido a baixo da sua temperatura (ou mais propriamente gama) de fusão, a cristalização tem início a partir dum certo número de centros de nucleação, sendo de considerar neste caso, dois aspectos principais: a existência de moléculas incorporadas em mais do que um cristalito, são moléculas de ligação e contribuem fortemente para a melhoria das propriedades mecânicas e a existência dum outro tipo de organização cristalina proveniente do crescimento dos cristalitos a partir dum centro de nucleação dando lugar a uma estrutura radial, simétrica, denominada esferulito. Os esferulitos são dum tamanho considerável e podem ser observados ao microscópio, em luz polarizada, sob a forma de "Cruz de Malta". (Ver Fig. 2)

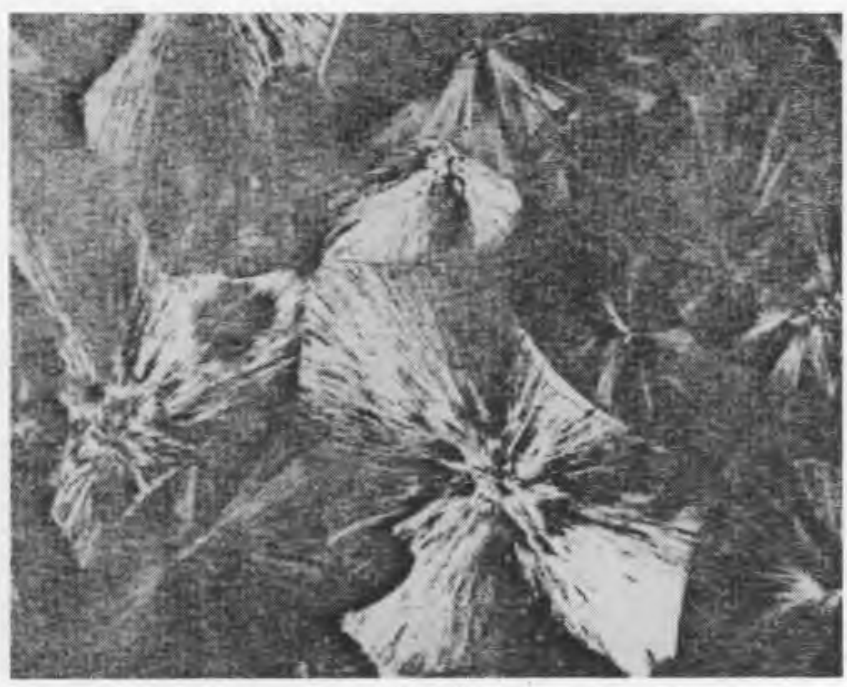

Fig. 2

Esferulitos de polipropileno isotático observados ao microscópio, com luz polarizada

A nucleação que conduz aos esferulitos pode ser originada por partículas estranhas (nucleação heterogénea, caso de aditivação especial para este fim) ou a partir de centros da própria massa do fundido (nucleação homogénea, moléculas que pelo seu tamanho ou posicionamento solidificam mais rapidamente).

O processo de cristalização envolve dois fenómenos consecutivos, a nucleação e a crescimento dos esferulitos, sendo ambos influenciados pela viscosidade do polímero fundido, temperatura (mais propriamente velocidade de arrefecimento) e pressão.

Dum modo geral, um grau de cristalinidade mais elevado conduz a valores mais elevados para o polímero, de densidade, rigidez, dureza, resistência à tracção, resistência aos solventes e impermeabilidade aos gases, provoca pelo contrário, menor resistência ao impacto e dificulta a sua dissolução.

Atendendo à influência que o maior ou menor grau de cristalinidade tem nas propriedades do polímero, é obvio que as condiçסes de transformação (dado envolverem sempre ciclos de temperatura e pressão) condiciona, em certa medida, as características do objecto produzido.

Daqui resulta a necessidade prática da avaliação das taxas de cristalinidade dos polímeros.

\section{2 - Métodos de estudo e determinação de taxa de cristalinidade}

As diferentes técnicas que podem ser utilizadas no estudo da morfologia dos polimeros são passíveis de ser reunidas em dois grupos:

\section{1) Primárias:}

Por imagem - microscopia optica e electrónica de transmissão.

Por difracção e "Scattering" - electrões, raios X, neutrōes, luz.

\section{2) Secundárias:}

- Análise térmica (DSC, ATD, análise gravimétrica), espectroscopia (Raman, infra-vermelho), análise de pesos moleculares.

Segundo o meio utilizado as dimensðes mínimas oberváveis são:

$$
\begin{aligned}
& \text { Electrőes }-0.1 \AA \\
& \text { Raios } \mathrm{X}-1 \AA \\
& \text { Neutroes }-1-10 \AA \\
& \text { Luz }-5000 \AA
\end{aligned}
$$

As dificuldades de aplicação e de interpretação dos resultados da maior parte destas técnicas não permite desenvolvê-las minimamente num trabalho do teor deste, que se pretende, simplesmente, como um alerta para todas estas questøes relacionadas com a caracterização dos polímeros.

Por esta razão vamos tentar explicar somente alguns pequenos apontamentos referentes aos resultados da aplicação de algumas destas técnicas.

\section{Difraç̧ão de Raios $X$}

Esta técnica é aplicável a todos os sólidos cristalinos ou amorfos e a todos os líquidos. No entanto, o poder de difraç̧ão dos raios $\mathrm{X}$ depende do número de electrōes do átomo. Quando esta técnica se aplica a um polímero cristalino, o diagrama mostra os dois tipos de "pattern" resultantes da existência de zonas cristalinas e amorfas.

Se a técnica aplicada é do tipo de difracção de raios $\mathrm{X}$ de ângulo largo, a informação obtida diz respeito ao tamanho das regiôes cristalinas e amorfas, à orientação e perfeição dos cristais e do arranjo das cadeias nos cristais.

No caso de ser aplicada a técnica de difracção de raios $\mathrm{X}$ de pequeno ângulo, a informação obtida é relativa às dimensð̃es externas das lamelas e dos esferulitos (se estes forem pequenos), à identificação das fases amorfa e cristalina e de vazios.

\section{Microscopia Electrónica}

O princípio da microscopia electrónica de transmissão é semelhante ao da microscopia em luz visível, com a diferença óbvia de que as lentes de vidro são substituídas por lentes electrostáticas ou electromagnéticas e que o feixe não é de luz visível mas um feixe de electrôs.

A preparação da amostra é, por vezes; particularmente difícil atendendo a que é necessário um provete extremamente fino. A aplicação da técnica também não é isenta de dificuldades pois, o feixe de electróes gera calor que pode alcançar temperaturas de $100-200^{\circ} \mathrm{C}$ às quais o polímero pode fundir e degradar, pelo que é preciso proteger a amostra e arrefecê-la.

Existem também as modalidade de microscopia electrónica de varrimento e de difracção.

\section{Microscopia Óptica}

No estudo dos polímeros cristalinos por microscopia optica, a técnica de mais fácil aplicação é a observação dos esferulitos, em luz polarizada, melhorada se se utilizar uma platina de aquecimento. Outras modalidades 
da microscopia optica tais como interferometria, microscopia de contraste de fase e birefrigência, são muito convenientes para o estudo da morfologia e orientação molecular.

Porque se trata de uma técnica que exige um equipamento relativamente mais acessível que a maior parte das outras, é bastante utilizado.

\section{Outros Métodos}

Passamos os métodos indicados como secundários, mais válidos no estudo do comportamento térmico dos polimeros, sem deixar de frizar que o comportamento térmico e a história térmica dum dado provete em observação, condicionam o seu estado de cristalinidade. Vamos dar um apontamento sobre um processo simples, prático que, para os termoplásticos fornece uma informação qualitativa com interesse - trata-se da medida da densidade. É fácil imaginar que, para um dado polímero, quanto maior for a taxa de cristalinidade maior será a sua densidade. O processo mais difundido é o que utiliza a coluna de gradiente de densidade; consiste em obter uma coluna de líquido, a partir de dois solventes completamente miscíveis, com um deter- minado gradiente de densidade. Esse gradiente é determinado e finalmente, introduzindo um provete do polimero amostra, na coluna, a partir da sua posição de equilíbrio é possível determinar a respectiva massa valúmica.

\section{3-CONCLUSÕES}

Neste breve trabalho pretendeu-se simplesmente focar algumas questð̋es relativas à caracterização de polímeros e às técnicas usadas para esse fim.

Dado que nenhuma delas tem um carácter absoluto, isto é, é suficiente para dar toda a informação necessária, quase sempre é preciso utilizar diversas técnicas. Por outro lado as técnicas apontadas são, dum modo geral, morosas exigindo preparação cuidada de amostras e análise detalhada dos resultados.

Os processos industriais, quer a produção de polímeros quer a transformação destes em objectos de utilização comum, não se compadecem com esta morosidade, pelo que habitualmente se determinam características mecânicas e termo-mecânicas, eléctricas e térmicas cujas correlaçð̌es, com os parâmetros estruturais, foram previamente estabelecidos. 